\title{
Mensurando a consciência ambiental do consumidor de moda Second Hand à luz da
}

\section{Escala NEP}

\author{
Measuring the environmental awareness of the Second Hand fashion consumer in light of the NEP
}

Scale

Medir la conciencia medioambiental del consumidor de moda de segunda mano a la luz de la Escala

\section{Resumo}

Trata-se de um trabalho sobre o comportamento do consumidor, em especial, daqueles que consomem produtos second hand, no segmento de moda, visto que as lojas de brechós, nos últimos anos tem aumentado significativamente seu papel no mercado de moda, com uma proposta, entre outros fatores, voltada à consciência ambiental. No Brasil, seguindo uma tendência mundial, o SERASA (2019) aponta que 3 pessoas, a cada dez entrevistados do seu banco de dados, afirmam ter consumido um produto usado no ano de 2019, via varejo, reforçando a importância de se conhecer melhor este consumidor e relacionar seu comportamento a uma atitude ambientalmente consciente. O objetivo da pesquisa é mensurar a consciência ambiental dos consumidores de uma determinada loja second hand, ou brechó, através da escala NEP, um instrumento validado no campo da pesquisa acadêmica sobre a consciência ambiental, que se apresenta em formato de formulário. Com a presente discussão busca-se responder ao seguinte questionamento: É possível afirmar que há consciência ambiental, por parte de consumidores de brechós? Almeja-se, através desta pesquisa obter indícios de consciência ambiental dos frequentadores deste tipo de loja second hand, visto que uma das vertentes que movem o consumo de produtos usados, apontada na literatura cientifica, é a abordagem crítica e ambientalmente consciente, ou socioambiental. A metodologia utilizou-se do questionário NEP, com pequenas adequações ao estudo, usando uma escala tipo likert (1-5), através de abordagens de coleta de dados pelo Google forms, com análise de dados através do software SPSS.

Palavras-chave: Consciência ambiental; Consumidor; Second Hand; Brechó.

\begin{abstract}
This is a work on consumer behavior, especially those who consume second-hand products, in the fashion segment, since thrift stores, in recent years, have significantly increased their role in the fashion market, with a proposal , among other factors, aimed at environmental awareness. In Brazil, following a global trend, SERASA (2019) points out that 3 people out of every ten respondents in its database claim to have consumed a used product in 2019, by retail stores, what reinforces the importance of how to know this better. Consumer and relate their behavior to an environmentally conscious attitude. The objective of the research is to measure the environmental awareness of consumers in a particular second-hand store, or thrift store, through the NEP scale, an instrument validated in the field of academic research on environmental awareness, which is presented in a form. With this discussion we seek to answer the following question: Is it possible to say that there is environmental awareness on the part of thrift shop consumers? It is intended, through this research, to obtain evidence of environmental awareness of the patrons of this type of second hand store, since one of the aspects that drive the consumption of used products, pointed out in the scientific literature, is the critical and environmentally conscious, or socio-environmental, approach. The methodology
\end{abstract}


used the NEP questionnaire, with minor adjustments to the study, using a Likert-type scale (1-5), through data collection approaches using Google forms, with data analysis using the SPSS software.

Keywords: Environmental awareness; Consumer; Second Hand; Thrift store.

\section{Resumen}

El reconocimiento de la innovación como uno de los principales impulsores de la competitividad y el desarrollo económico ha llamado la atención de académicos, emprendedores y formuladores de políticas públicas para identificar los factores que impiden que las organizaciones innoven o logren el éxito con sus innovaciones. Este estudio tiene como objetivo investigar la literatura científica sobre los obstáculos a la innovación en Brasil en los últimos diez años (2010 a 2020). La investigación, con un enfoque cuantitativo, se clasifica como descriptiva-exploratoria, y utiliza el análisis de conglomerados y el análisis factorial exploratorio para el procesamiento de datos. La encuesta de artículos para análisis resultó en 43 publicaciones en las bases de datos Web of Science y Scopus. Los principales resultados obtenidos del análisis factorial y de conglomerados sugieren que los principales obstáculos a la innovación en Brasil discutidos en la literatura son los altos costos de la innovación, la falta de personal calificado, los riesgos económicos y la escasez de financiamiento.

Palabras clave: Conciencia ambiental; Consumidor; Tienda de segunda.

\section{Introdução}

O comportamento do consumidor de moda vem mudando ao longo do tempo, ampliando horizontes e aderindo, de forma mais contundente, no século XXI, a ideia de moda sustentável, adotando em alguns casos ao Slow Fashion e o consumo de produtos de moda second hand.

Assim como no mundo inteiro, no Brasil, o aumento de lojas de moda second hand sejam físicas, ou virtuais, sinalizam atenção e despertam no consumidor final uma oportunidade de consumo consciente. Essa tendência de moda sustentável, ganha espaço e traz à tona possibilidades de um novo mercado que consiste na venda de produtos usados, outrora estigmatizado; agora, ganham espaço e são elegidos à modelos de negócio do futuro.

Para se ter ideia da dimensão deste mercado, dados do NARTS- Associação de Profissionais de Revenda dos EUA, apontam que entre 2018-2019, os negócios de second hand cresceram 11\%, somente no país. No Brasil, o SERASA aponta que 3 pessoas, a cada dez entrevistados do seu banco de dados, afirmam ter consumido um produto usado no ano de 2019, via varejo. Tais dados elevam os negócios de produtos usados ao um status de relevância gerencial, passando a despertar interesses de grandes varejistas como a Renner, que ousou em parceria com o Brechó on-line Repassa, apostando no segmento second hand de moda (Valor, 2020).

Diante da importância descrita, o comportamento do consumidor de produtos second hand, passa a despertar o interesse por pesquisas no sentido de conhecê-lo, compreendê-lo e buscar formas de criar valor. Mas, uma questão de relevância permeia o consumo de produtos usados, que é a sua relação com a consciência ambiental. Isto porque, cada vez mais, uma boa parcela dos consumidores estão tornando-se mais exigentes com relação à dimensão ambiental de produtos e serviços.

E, a partir daí questiona-se: qual o nível de consciência ambiental, por parte de consumidores de brechós? Esta interrogação permeia reflexão da literatura sobre negócios second hand, que subsidia sua plataforma teórica em três pilares: consumo com base no preço, de caráter econômico; consumo recreativo, de caráter hedônico; e, consumo consciente, de caráter socioambiental. Este último aspecto é o que se deseja abordar no estudo.

Esta pesquisa busca expor a relação que existe entre o consumo consciente e os brechós, apontando para uma existência ou não de consciência ambiental por parte de seus consumidores. Isto porque, em uma breve investigação bibliométrica no Portal de Periódicos da Capes (início de 2021), fonte de dados para levantamento bibliográfico utilizada no trabalho, pouco se relaciona as temáticas, apesar de seu grande entrelaçamento em termo de área de pesquisa da sustentabilidade. 
O objetivo da pesquisa é então observar se é possível mensurar a existência de consciência ambiental em se tratando de consumidores de lojas second hand de moda, visto que dentre os apelos ao consumo de produtos usados, e no segmento de vestuário, em especial, um deles é o consumo crítico, baseado em preceitos de responsabilidade social e ambiental.

No caso do presente estudo, foi utilizada a escala New Environmental Paradigm - NEP (Dunlap \& Van Liere, 1978), uma escala que busca mensurar a consciência ambiental, amparado em 15 assertivas sobre o tema tríade "homemcomportamento-ambiente". A escala NEP é referenciada mundialmente e tem boa aceitação nas pesquisas sobre consumo consciente. Desta forma, em razão de sua funcionalidade resolveu-se adotar a escala NEP para mensurar o nível de consciência ambiental dos frequentadores de brechó, no caso em especial.

Além disso, a metodologia optou por o desenvolvimento de uma pesquisa quantitativa, com o levantamento de dados primários, colhidos através de questionários, enviados via Instagram, aos seguidores de um brechó, na cidade de João PessoaPB. O questionário tem como base a escala NEP e foi organizado via Google forms, recebendo o tratamento estatístico via software SPSS.

\subsection{O comportamento do consumidor second hand e a consciência ambiental}

A administração possui inúmeros segmentos a serem tratados na gestão de empresas e um deles, emerge na área de marketing, como um dos principais elementos, para os mais diversos tipos de negócios: o comportamento do consumidor. O comportamento do consumidor é considerado uma parte fundamental para a compreensão do todo, de uma organização, abraçando suas perspectivas externas, focando em uma de suas principais atividades que é a criação de valor para o cliente (Kotler, 2006; Rocha \& Rocha, 2007).

Esse comportamento do consumidor possui abordagens variadas, a exemplo da definição trazida por Kotler (2006) na qual descreve comportamento do consumidor como o de pessoas, grupos e organizações que selecionam, compram, usam e descartam produtos, serviços, ideias ou experiências para satisfazer suas necessidades e seus desejo. Em sentido semelhante, temos que para Solomon (2011, p. 33) o comportamento do consumidor é compreendido como um processo no qual os "indivíduos, ou grupos, usam ou descartam, produtos, serviços ideias, e experiências para satisfazer suas necessidades e desejos".

Nesse sentido, um dos principais focos do estudo do comportamento do consumidor é entender quais os fatores que influenciam o seu processo de compra e os porquês da tomada de decisão, sobre determinada compra. E, é aqui, que entra a questão da consciência ambiental na hora de concretizar uma compra. Essa preocupação com as questões ambientais promove o surgimento de um novo tipo de consumidor que, foca suas ações de compra em produtos e serviços com o diferencial de não interferir nocivamente no meio ambiente, são os consumidores verdes, ou os ambientalmente conscientes (De Toni et al., 2012; Pereira, 2013).

Uma descrição apropriada e objetiva para o consumidor consciente é aquela na qual o consumidor consciente apresenta-se como aquele cuja "preocupação também está com outras pessoas, com as gerações futuras e com a expectativa de estar contribuindo com a melhoria da qualidade de vida de todos" (De Toni et al., 2012, p.141 apud Anderson Jr.; Cunningham, 1972).

Esse consumo consciente, ou ambientalmente consciente, emerge na literatura de gestão no final da década de 1990, segundo Rocha e Rocha (2007), contudo, no mundo inteiro já se falava em consumo, consumismo, consumo consciente, sustentabilidade na tomada de decisão de compras, entre outras abordagens do gênero, desde o início do século XX, principalmente com um direcionamento voltado às estratégias de diferenciação, por ser percebida como uma vantagem competitiva (Pereira \& Ayrosa, 2004; Pereira, 2013; Robert, 1996 e 1997). 
Um marco no pensamento ecologicamente correto no sentido do consumo foi em 1972 (Sachs, 2002; Santos 2002), com a Conferência das Nações Unidas sobre o Meio Ambiente Humano, também conhecida como Conferência de Estocolmo, na qual foram discutidas de forma livre, envolvendo o mundo inteiro, diversas questões que implicariam em um desenvolvimento sustentável, inaugurando formalmente o termo sustentabilidade, que embasa o cerne da questão do consumo consciente. Essa perspectiva é reforçada, em 1987, com a Conferência da ONU- Organização das Nações Unidas, da qual aflora o Relatório "Nosso Futuro Comum".

No Brasil, a ECO-92, consta como um marcador cronológico e de posicionamento do governo, dos gestores empresariais e do cidadão brasileiro, frente às questões ambientais, sendo considerado um encontro de envergadura internacional sobre os temas ambientais e climáticos (Santos, 2002). Na década de 1990, o Brasil passa a compor a engrenagem mundial de países com abordagens focadas na responsabilidade socioambiental, sendo o período de maior produção de legislação protetiva e diretiva sobre a esfera ambiental (Antunes, 2015).

Outro passo importante para a incessante busca pelo comportamento ambientalmente consciente foi a ONU, em 2015, que lança a Agenda 2030, uma releitura da Agenda21, composta pelos Objetivos de Desenvolvimento do Sustentável (ODS), na qual dispõe os 17 objetivos e 169 metas para alcançar o Desenvolvimento Sustentado, tão almejado, nas mais diversas área, envolvendo pessoas, meio ambiente e empresas e governança, com intuito de fomentar as boas práticas de desenvolvimento sustentável (Organização das Nações Unidas [ONU], 2015).

Assim, nos últimos anos, temos as crescentes campanhas de grupos não governamentais, bem como de organizações governamentais, por adoção de comportamentos sustentáveis por parte dos cidadãos. Essa tendência, é seguida pelas empresas, que adotam comportamentos socialmente e ambientalmente responsáveis, que inicialmente surgem como uma obrigação legal, mas tomam uma forma mais robustas através das perspectivas estratégicas de compor sua imagem junto aos seus consumidores.

Neste cenário, o segmento de vestuário, possui uma grande envergadura no mercado global, e no Brasil não é diferente. A produção de roupas é um negócio gerador de renda significativa para a economia, mas também, assume um impacto ambiental grave em seu processamento (Instituto AKATU). Dados sobre o comércio de vestuário no Brasil apontam uma considerável queda no ano de 2020, em razão da pandemia, conforme SBVT (Sociedade Brasileira de vestuário e Têxtil) que prevendo uma retração de $18 \%$ de queda nas arrecadações do setor, entretanto, ainda com uma arrecadação de $\mathrm{R} \$ 152,1 \mathrm{Bi}$, e uma produção de 4,7bilhões de peças novas (Associação de Indústrias Têxtil e de Confecção Brasileira [ABIT], 2020).

A magnitude do setor têxtil e de vestuário impressiona por alcance, números e impactos, sendo este mesmo segmento de mercado, o de produção de roupas e acessórios têxtil, responsáveis por uma intensa poluição ambiental. Esse mercado da moda, como é globalmente tratado, afeta o meio ambiente e faz refletir sobre a necessidade de se encontrar vias alternativas de consumo, como as second hand store, ou os brechós.

Para se compreender melhor a questão, a ONU (2019) traz dados sobre a indústria da moda e sua gestão com relação aos impactos ambientais. A indústria da moda responde por algo entre $8 \%$ e $10 \%$ das emissões globais de gases-estufa, isso é mais que a aviação e o transporte marítimo, juntos. É o segundo setor da economia que mais consome água e produz cerca de $20 \%$ das águas residuais do mundo, liberando 500 mil toneladas de microfibras sintéticas nos oceanos todos os anos, ocasionando um impacto ambiental significativo (Sánchez-Vázquez, 2020; Valor, 2019).

Diante destes itens apontados, não resta dúvidas de que a moda é um grande agente de impacto ambiental, e que o fast fashion, uma conduta de empresas e consumidores por consumir cada vez mais em menor tempo, segue no sentido de ser repensada, abrindo espaço para outras opções como o Slow Fashion e o upcycling (Saffi, 2015; Fletcher, 2011; Mcquillan, 2011). O consumidor do futuro se prepara para compras mais conscientes e cujo impacto ambiental possa ser minorado ou 
eliminado. Pode-se dizer que esta é uma tendência, contudo, ressalva-se que o fast fashion e o consumo de produtos sem apelo ambiental, ainda tem participação dominante no mercado da moda.

Mas, é neste cenário de mudança de comportamento do consumidor, que hoje temos um espaço crescente no segmento de moda second hand. Os conhecidos brechós passam a ocupar um lugar de destaque no mercado de roupas e acessórios, inspirando uma opção de consumo consciente.

Contudo, insta observar que o comércio de produtos second hand possui uma história bem anterior aos apelos sustentáveis do último século, datando seus primeiros registros formais do sec. XVIII, na Europa, compatível aos nascimentos dos primeiros mercados de pulgas, que ao longo dos anos se espalharam por todo o mundo, enfrentando um período de declínio no século XX e no início do século XXI, uma ascensão importante, em razão da onda do consumo sustentável e consciente (Guiot \& Roux, 2008; Willians, 2003). É preciso registrar que o comércio second hand é amplo e variado, compreendendo desde navios e carros, bem como eletroeletrônicos, e roupas e acessórios, foco deste trabalho.

Conforme Hansen e Zott (2019), os brechós second hand, adotam uma nova perspectiva de negócios. Segundo os autores, as novas lojas que realizam esta revenda ajudam a criar um novo tipo de negócio, com a essência dos primeiros mercados de pulga europeus, mas com a nova forma americana de varejo, trazendo novas nuances para este tipo de produto, além de mais uma oportunidade ao consumidor.

E, no caso da literatura sobre second hand, quando verifica-se as abordagens sobre o tema, a relação com o comportamento do consumidor esta presente entre os temas debatidos. Isto ocorre porque comprar usados desafia as possibilidades de novas perspectivas gerenciais. Os impactos do second hand na criação de novos negócios, na mudança de hábitos dos consumidores e nas questões econômicas em geral são interessantes e estão cada vez mais despertando atenção de estudos.

A teoria que norteia os negócios second hand ainda é recente sob a óptica da discussão acadêmica; mas, já delimita alguns espaços de atuação como os três panoramas de abordagens motivacionais para consumo second hand. A motivação econômica, baseada no menor preço; a motivação recreativa, baseada nas experiências de achar um tesouro, uma raridade junto a produtos antigos e usados; e, na experiência crítica, baseada na consciência ambiental e na responsabilidade social, sendo esta última o foco desta pesquisa (Guiot \& Roux, 2008; Willians, 2003; Hansen \& Zott, 2019).

\section{Metodologia}

Trata-se de uma pesquisa quantitativa, de natureza descritiva, na qual buscou-se mensurar o nível da consciência ambiental de consumidores de brechós de moda. Para a coleta de dados foi utilizado o questionário da escala NEP, com acréscimos de algumas perguntas de aspectos gerais e descritivos, para desenhar o perfil do consumidor de moda em brechós.

Os questionários foram enviados através da plataforma digital do Instagram, para 200 seguidores de dois brechós, da cidade de João Pessoa-PB. O envio ocorreu de forma aleatória, uma vez que esperava-se compor uma amostra heterogênea. Os brechós foram escolhidos por terem mais de 30 mil seguidos, sinalizando visibilidade daquela marca de produtos second hand, na região e no ambiente virtual.

Os questionários foram estruturados por meio do Google forms, e os links, foram distribuídos, por um período de 45 dias (de 20 de janeiro à 06 de março de 2021). Fez-se um direcionamento dos questionários para 50\% de respondentes masculinos, e 50\% de respondentes do gênero feminino. No tocante a estruturação dos questionários, usou-se as assertivas dispostas na Tabela NEP e inseriu-se um marcador no tipo likert, variando em: concordância total à discordância total.

O tratamento dos dados ocorreu no SPSS 26, através de aplicação de uma estatística descritiva para gerar resultados sobre as informações coletadas, com base nas respostas aos itens da escala NEP e, também, para a questão gênero, escolaridade, e frequência de compras em brechó. 


\subsection{Escala NEP}

A consciência ambiental é algo que está no cerne das preocupações das organizações. Um movimento crescente entre parte da população mundial que adquire padrões de reflexão e consciência, principalmente, quanto ao seu comportamento de consumidor, exigindo-se que cada vez mais a relação consumo consciente e consciência ambiental estejam interligados. Pensando nessa questão, Dunlap e Van Liere, em 1978, desenvolveram uma escala que procura mensurar a consciência ambiental do consumidor (Dunlap et al., 2000).

Dentre outros estudiosos do tema, os autores Riley Dunlap e Kent D. Van Liere, em 1978, se destacam por suas pesquisas que relacionam economia e meio ambiente, apresentando-se como um contraponto ao antigo paradigma que prevalência na ciência até a década de 1960, com a ideia de uma crença nos recursos naturais ilimitados, do homem independente da natureza e da soberania tecnológica, coadunando com o então PSD (paradigma sócio industrial dominante) (Pirages \& Ehrlich, 1974).

Há desde então, o nascimento de um novo paradigma, que aponta para a importância do papel do meio ambiente no sistema econômico e na sociedade, desenhando um 'Novo Paradigma Sócio- Ambiental'. Os autores, com base nesta nova premissa, propuseram o NEP - Novo Paradigma de Desenvolvimento', de forma inicial; e, posteriormente o NEP- 'Novo Paradigma Ecológico', que se contrapunha ao paradigma até então vigente em grande parte da sociedade ocidental (Van Liere et al., 2000).

A escala NEP, Novo Paradigma Ecológico, ganha espaço em razão das críticas ao antigo modelo, mas insta observar que, o modelo final desta escala foi desenvolvido entre os anos de 1978 a 2000 e, somente depois de quase 20 anos de estudos e validações, a escala NEP assume sua estrutura atual, composta por 15 itens, com uma amplitude de respostas baseada em escala tipo likert, variando de um a cinco (Dunlap et al., 2000).

Na construção da tabela de mensuração NEP, foram usadas cinco grupos (dimensões) hipotéticos de percepção do mundo ecológico, oriundos de outras pesquisas anteriores a composição do construto. Conforme a metodologia de desenvolvimento da tabela NEP por Dunlap e Van Liere (1980; 2000) a escala possui 15 itens agrupados da seguinte forma: Ia realidade do limite do crescimento (itens 1, 6 e 11); II- anti-antropocentrismo (itens 2,7 e 12); III- a fragilidade do equilíbrio natural (itens 3,8 e 13); IV- exclusão do ser humano da natureza (itens 4, 9 e 14); V- Iminência de crise ecológica (itens 10, 15 e 5). É possível visualizar a escala NEP, no Quadro 1. 
Quadro 1: Escala NEP.

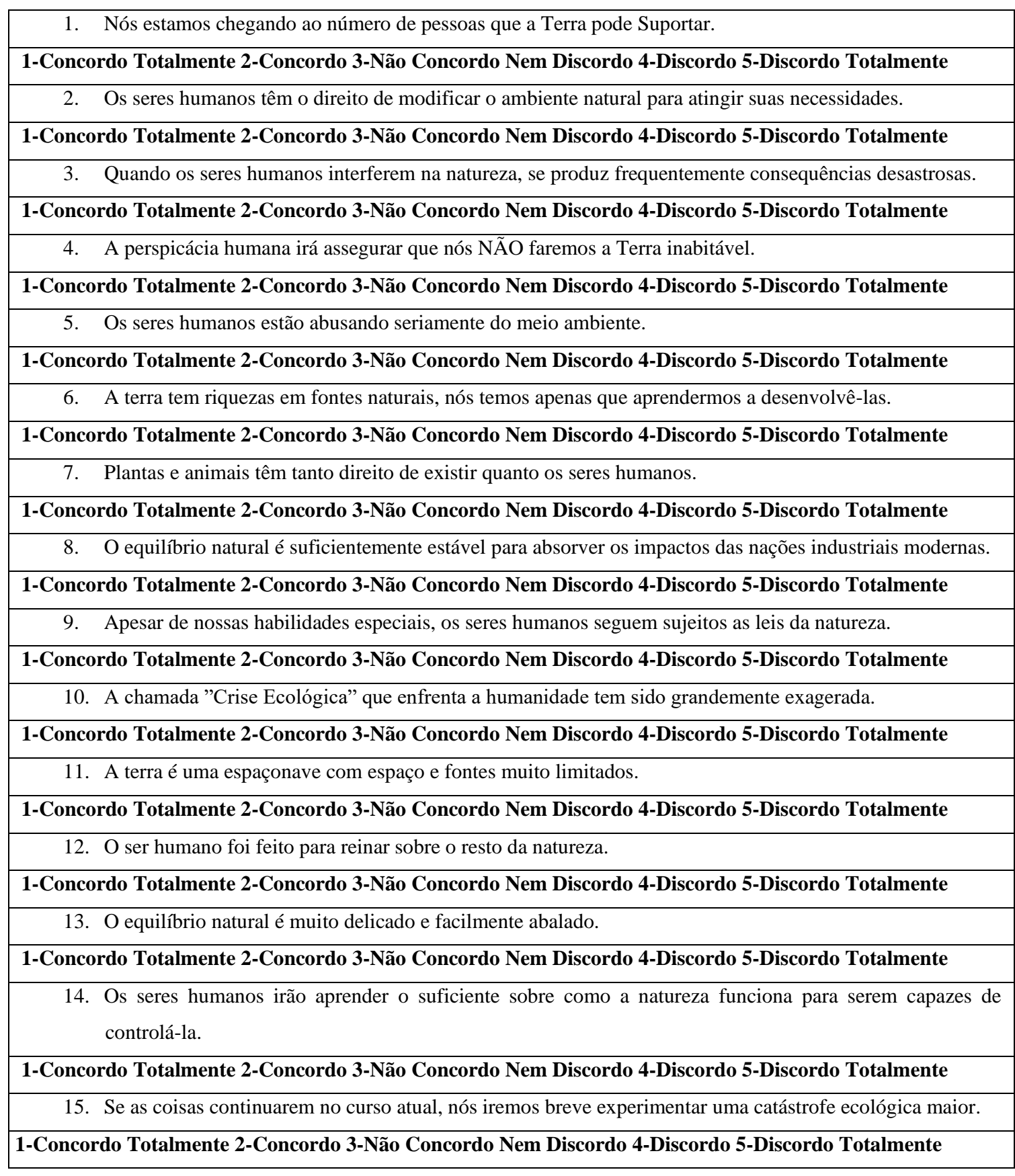

Fonte: Adaptado de Dunlap et al. (2000).

\section{Resultados e Discussão}

As análises efetuadas apresentaram resultados com base em 104 respondentes, sendo 74 do gênero feminino e 30 do gênero masculino. Assim, delinear o perfil do grupo que subsidia as informações apontando uma faixa etária é importante na maior parte dos estudos transversais que trabalham a mensuração determinado quesito, como a consciência ambiental, trazido pela escala NEP.

Neste sentido, inicialmente observa-se a faixa etária dos respondentes como sendo em média 28 anos para o gênero feminino e 37 para o gênero masculino, conforme Tabelas 1 e 2 . A idade pode ser considerada um dado interessante, posto que confirma a procura por roupas second hand por um público de faixa etária mais jovem (William, 2003), corroborando uma tendência mais geral sobre o comportamento do consumidor, a Tabela 3 apresenta a frequência de compras em brechós. 
Tabela 1: Gênero e idade dos respondentes.

\begin{tabular}{l|l|l}
\hline & Feminino $(\mathbf{n}=\mathbf{7 4})$ & Masculino $(\mathbf{n}=\mathbf{3 0})$ \\
\hline \multirow{2}{*}{ Idade } & $30,89 \pm 1,405$ & $37,17 \pm 1,92$ \\
& $28(19-67)$ & $37(19-68)$ \\
\hline
\end{tabular}

Fonte: Autoria própria (2021).

Tabela 2: Escolaridade dos respondentes.

\begin{tabular}{|c|c|c|c|c|c|c|c|}
\hline Escolaridade & \multicolumn{3}{|c|}{ 1= Médio 2=Superior 3= Pós-graduação } & 1 & 2 & 3 & Total \\
\hline \multirow{4}{*}{$\begin{array}{l}\text { Gênero } \\
1=\mathrm{F} 2=\mathrm{M}\end{array}$} & \multirow{2}{*}{1} & \multicolumn{2}{|l|}{ Contagem } & 14 & 33 & 27 & 74 \\
\hline & & \% em Gênero & $1=\mathrm{F} 2=\mathrm{M}$ & $19,2 \%$ & $45,2 \%$ & $35,6 \%$ & $100,0 \%$ \\
\hline & \multirow{2}{*}{2} & Contagem & & 0 & 16 & 14 & 30 \\
\hline & & \% em Gênero & $1=\mathrm{F} 2=\mathrm{M}$ & $0,0 \%$ & $53,3 \%$ & $46,7 \%$ & $100,0 \%$ \\
\hline \multirow{2}{*}{ Total } & & Contagem & & 14 & 49 & 41 & 104 \\
\hline & & \% em Gênero & $1=\mathrm{F} 2=\mathrm{M}$ & $13,6 \%$ & $47,6 \%$ & $38,8 \%$ & $100,0 \%$ \\
\hline
\end{tabular}

Fonte: Autoria própria (2021).

Tabela 3: Frequência de compras em brechós.

\begin{tabular}{l|l|l|l|l|l|l|l|l}
\hline $\begin{array}{l}\text { Escala } \\
\text { Perguntas }\end{array}$ & 1 & 2 & 3 & 4 & 5 & Média (Moda) & Variância & Total de respondentes \\
\hline SECOND.HAND & $\begin{array}{l}23 \\
(22,1 \%)\end{array}$ & $\begin{array}{l}45 \\
(43,3 \%)\end{array}$ & $\begin{array}{l}14 \\
(13,5 \%)\end{array}$ & $\begin{array}{l}20 \\
(19,2 \%)\end{array}$ & $\begin{array}{l}2 \\
(1,9 \%)\end{array}$ & $2,36(2)$ & 1,183 & 104 \\
\hline
\end{tabular}

Fonte: Autoria própria (2021).

Os dados acima apresentados contribuem para a visualização do perfil dos respondentes, podendo-se destacar a maioria do gênero feminino, entre 19 e 67 anos, com média de 28 anos de idade, e que possuem nível superior de escolaridade, e que costumam comprar com frequência em brechós. Mais uma vez, os dados suplementando as informações de que o público alvo de brechós é formado em sua maior parte por mulheres, com menos de 30 anos e com alguma graduação, são importantes para compreender outras questões em torno deste público alvo.

Na sequência, foi realizado uma Análise Fatorial Exploratória (AFE) para mensurar a consciência ambiental destes respondentes, segmentando a amostra por um grupo de escolha aleatória, na qual não se tinha nenhum outro dado prévio sobre as características deste grupo.

Para conferir robustez ao teste, aplicou-se uma estatística de confiabilidade, optando-se pelo teste de Cronbach. Esse teste é um índice utilizado para medir a confiabilidade do tipo consistência interna de uma escala, ou seja, para avaliar a magnitude em que os itens de um instrumento estão correlacionados (Cortina, 1993). Conforme Tabela 4:

Tabela 4: Estatística de confiabilidade.

\begin{tabular}{l|l|l}
\hline \multicolumn{2}{l}{ Estatísticas de confiabilidade } \\
\hline Alfa de Cronbach & Alfa de Cronbach com base em itens padronizados & N de itens \\
\hline, 384 &, 430 & 16 \\
\hline
\end{tabular}

Fonte: Autoria própria (2021). 
OBS: Valores entre 0 a $0,21=$ confiabilidade pequena; 0,21 a $0,40=$ confiabilidade razoável; 0,41 a 0,60 confiabilidade moderada; 0,61 a $0,80=$ confiabilidade substancial; 0,81 a $1,0=$ confiabilidade quase perfeita.

A confiabilidade moderada indica que os dados são satisfatórios e o teste mostrou-se adequado para uma Análise Fatorial Exploratória. A sig. 0,430 permite a confiança no tratamento dos dados através de uma AFE, a qual foi realizada conforme coleta de dados através da escala NEP, via formulário eletrônico, anteriormente mencionado.

Indicadores da Escala NEP no Quadro 2:

Quadro 2: Indicadores da Escala NEP.

\begin{tabular}{|c|c|c|c|c|c|c|c|c|}
\hline \multirow{2}{*}{$\begin{array}{l}\text { Escala } \\
\text { Perguntas }\end{array}$} & \multirow[b]{2}{*}{1} & \multirow[b]{2}{*}{2} & \multirow[b]{2}{*}{3} & \multirow[b]{2}{*}{4} & \multirow[b]{2}{*}{5} & \multirow{2}{*}{$\begin{array}{l}\text { Mé } \\
\text { Mo }\end{array}$} & \multirow[b]{2}{*}{$\begin{array}{l}\text { Variân } \\
\text { cia }\end{array}$} & \multirow{2}{*}{$\begin{array}{l}\text { Total de } \\
\text { responde } \\
\text { ntes }\end{array}$} \\
\hline & & & & & & & & \\
\hline $\begin{array}{l}1 \\
\text { PESSOAS.NA.TERRA }\end{array}$ & $30(28,8 \%)$ & $50(48, \%)$ & $1(10,6 \%)$ & $07(6,7 \%)$ & $06(5,8 \%)$ & $2,13(2)$ & 1,178 & 104 \\
\hline $\begin{array}{l}2 \\
\text { MODIFICAR. } \\
\text { AMBIENTE. } \\
\text { NATURAL }\end{array}$ & $04(3,8 \%)$ & $28(26,9 \%)$ & $27(26,0 \%)$ & $31(29,8 \%$ & $14(13,5 \%)$ & $3,22(4)$ & 1,222 & 104 \\
\hline $\begin{array}{l}3 \\
\text { CONSEQUÊNCIAS. } \\
\text { DESASTROSAS }\end{array}$ & $45(43,3 \%)$ & $35(33,7 \%)$ & $11(10,6 \%)$ & $13(12,5 \%)$ & $0(0,0 \%)$ & $1,92(1)$ & 1,043 & 104 \\
\hline $\begin{array}{l}4 \\
\text { TERRA.NÃO. } \\
\text { HABITÁVEL }\end{array}$ & $09(8,7 \%)$ & $28(26,9 \%)$ & $20(19,2 \%)$ & $30(28,8 \%)$ & $15(14,4 \%)$ & $3,14(4)$ & 1,506 & $104-2$ \\
\hline $\begin{array}{l}5 \\
\text { ABUSO.MEIO. } \\
\text { AMBIENTE } \\
\end{array}$ & $60(57,7 \%)$ & $35(33,7 \%)$ & $04(3,8 \%)$ & $05(4,8 \%)$ & $0(0,0 \%)$ & $1,56(1)$ & 0,618 & 104 \\
\hline $\begin{array}{l}6 \\
\text { RIQUEZAS. } \\
\text { NATURAIS } \\
\end{array}$ & $27(26,0 \%)$ & $45(43,3 \%)$ & $17(16,3 \%)$ & $14(13,5 \%)$ & $01(1,0 \%)$ & $2,20(2)$ & 1,017 & 104 \\
\hline $\begin{array}{l}7 \\
\text { PLANTAS.ANIMAIS.D } \\
\text { IREITOS }\end{array}$ & $66(63,5 \%)$ & $28(26,9 \%)$ & $03(2,9 \%)$ & $06(5,8 \%)$ & $0(0,0 \%)$ & $1,50(1)$ & 0,664 & $104-1$ \\
\hline $\begin{array}{l}8 \\
\text { AQUILÍBRIO } \\
\text {.NATURAL }\end{array}$ & $04(3,8 \%)$ & $20(19,2 \%)$ & $13(12,5 \%)$ & $28(26,9 \%)$ & $39(37,5 \%)$ & $3,75(5)$ & 1,568 & 104 \\
\hline $\begin{array}{l}9 \\
\text { HUMANOS.LEIS. } \\
\text { DA.NATUREZA }\end{array}$ & $36(34,6 \%)$ & $37(35,6 \%)$ & $21(20,2 \%)$ & $08(7,7 \%)$ & $02(1,9 \%)$ & 2,07 (2) & 1,034 & 104 \\
\hline $\begin{array}{l}10 \\
\text { CRISE.ECOLÓGICA }\end{array}$ & $04(3,8 \%)$ & $13(12,5 \%)$ & $17(16,3 \%)$ & $35(33,7 \%)$ & $35(33,7 \%)$ & $3,81(4 *)$ & 1,322 & 104 \\
\hline $\begin{array}{l}11 \\
\text { TERRA. } \\
\text { ESPAÇONAVE }\end{array}$ & $26(25,0 \%)$ & $34(32,7 \%)$ & $29(27,9 \%)$ & $10(9,6 \%)$ & $04(3,8 \%)$ & $2,34(2)$ & 1,168 & $104-1$ \\
\hline $\begin{array}{l}12 \\
\text { HUMANOS.REINAM }\end{array}$ & $05(4,8 \%)$ & $18(17,3 \%)$ & $13(12,5 \%)$ & $28(26,9 \%)$ & $39(37,5 \%)$ & $3,76(5)$ & 1,597 & 104-1 \\
\hline $\begin{array}{l}13 \\
\text { EQUILÍBRIO. } \\
\text { ABALADO }\end{array}$ & $27(26,0 \%)$ & $57(54,8 \%)$ & $13(12,5 \%)$ & $07(6,7 \%)$ & $0(0,0 \%)$ & $2,0(2)$ & 0,660 & 104 \\
\hline $\begin{array}{l}14 \\
\text { HUMANO.CONTROL } \\
\text { A.NATUREZA }\end{array}$ & $02(1,9 \%)$ & $34(32,7 \%)$ & $28(26,9 \%)$ & $27(26,0 \%)$ & $13(12,5 \%)$ & $3,14(2)$ & 1,154 & 104 \\
\hline $\begin{array}{l}15 \\
\text { CATÁSTROFE. } \\
\text { ECOLÓGICA }\end{array}$ & $51(49,0 \%)$ & $41(39,4 \%)$ & $05(4,8 \%)$ & $06(5,8 \%)$ & $0(0,0 \%)$ & 1,67 (1) & 0,674 & $104-1$ \\
\hline
\end{tabular}

Fonte: Autoria própria (2021).

A tabela 06 é composta por resultados da aplicação dos formulários com base a escala NEP, fornecendo os resultados supra descritos. E, diante destes achados, pode-se agrupar as compreensões em 5 dimensões estruturadas pelo próprio questionário NEP (Dunlap et al., 2000). 
A dimensão I indica a realidade do limite do crescimento, ou seja, como as pessoas percebem os limites do planeta, e são compostos pelos itens 1, 6 e 11, mencionados na Tabela 2. E, neste caso, é possível afirmar pela exposição dos dados relativos à tabela 06 que há uma disposição a concordância sobre o fato de haver um limite para tudo tipo de ação humana que a terra pode suportar, expondo o item 1, que possui $48 \%$ de concordância dos respondentes (De Toni, 2012; Silva Filho et al., 2010; Roberts, 1997; Pereira, 2004).

A dimensão II que intitula-se anti-antropocentrismo, é composto pelos itens 2,7 e 12. Para esclarecer, o antropocentrismo é um sistema filosófico e de crenças religiosas que atribui ao ser humano uma posição de centralidade em relação a todo o universo. Esse anti-antropocentrismo, sugere, exatamente uma concepção de que o homem não é o centro do universo e sim mais um átomo dentro dele, com o aporte dentre outras perguntas que indagam se plantas e animais tem o mesmo direito de existir quanto os homens (De Toni, 2012; Silva Filho et al., 2010; Roberts, 1997; Pereira, 2004).

Nos dados obtidos, pode verificar que no item 7 sobre os seres humanos terem o direito de modificar o ambiente natural para atingir suas necessidades houve uma maior incidência no tocante a discordância, refletindo que a ação de modificar de forma indiscriminada o ambiente natural é reprovável. Reforçando a ideia de limitação dos recursos naturais.

A divisão categorizou na dimensão III, a fragilidade do equilíbrio natural, incluindo aí os itens 3,8 e 13, que abordam a tese de que o ecossistema é uma engrenagem equilibrada e fragilmente pode ser desestruturada, quando se trata da degradação e ação imprudente do homem sobre a natureza, obtendo-se respostas positivas na maior parte dos quesitos. Demonstrando a compreensão de fatos degradantes podem trazer consequências nocivas e que desequilibram o ecossistema.

A dimensão IV traz a ideia da exclusão do ser humano da natureza, sendo composto pelos itens 4, 9 e 14, onde gera a reflexão sobre a possibilidade de vida para o homem sem a terra. Traz a toma questões sobre a possibilidade do homem controlar a terra, mesmo diante das respostas naturais. Opinando a maior parte dos respondentes pela impossibilidade da existência deste controle total.

E, por fim, a dimensão V que versa sobre a Iminência de crise ecológica, composto pelos itens 10, 15 e 5, apontam que mais da metade dos respondentes acreditam que estaríamos a beira de uma catástrofe ecológica. Evidenciando uma preocupação com as condições do planeta. Conforme Tabela 5:

Tabela 5: Variância Total Explicada.

\begin{tabular}{|c|c|c|c|c|c|c|c|c|c|}
\hline \multirow[b]{2}{*}{ Componente } & \multicolumn{3}{|c|}{ Autovalores iniciais } & \multicolumn{3}{|c|}{$\begin{array}{l}\text { Somas de extração de carregamentos ao } \\
\text { quadrado }\end{array}$} & \multicolumn{3}{|c|}{$\begin{array}{l}\text { Somas de rotação de carregamentos ao } \\
\text { quadrado }\end{array}$} \\
\hline & Total & variância $\mathrm{de}$ & $\begin{array}{l}\% \\
\text { cumulativa }\end{array}$ & Total & \% de variância & $\%$ cumulativa & Total & \% de variância & $\%$ cumulativa \\
\hline 1 & 4,007 & 25,042 & 25,042 & 4,007 & 25,042 & 25,042 & 3,444 & 21,525 & 21,525 \\
\hline 2 & 2,063 & 12,894 & 37,936 & 2,063 & 12,894 & 37,936 & 2,314 & 14,464 & 35,990 \\
\hline 3 & 1,596 & 9,973 & 47,909 & 1,596 & 9,973 & 47,909 & 1,679 & 10,496 & 46,486 \\
\hline 4 & 1,239 & 7,742 & 55,651 & 1,239 & 7,742 & 55,651 & 1,284 & 8,026 & 54,511 \\
\hline 5 & 1,033 & 6,459 & 62,110 & 1,033 & 6,459 & 62,110 & 1,216 & 7,599 & 62,110 \\
\hline 6 &, 865 & 5,408 & 67,519 & & & & & & \\
\hline 7 &, 751 & 4,696 & 72,215 & & & & & & \\
\hline 8 & ,736 & 4,602 & 76,817 & & & & & & \\
\hline 9 & ,651 & 4,067 & 80,884 & & & & & & \\
\hline 10 &, 573 & 3,583 & 84,467 & & & & & & \\
\hline 11 &, 530 & 3,314 & 87,780 & & & & & & \\
\hline 12 & 485 & 3,031 & 90,811 & & & & & & \\
\hline 13 & 463 & 2,892 & 93,703 & & & & & & \\
\hline 14 & ,362 & 2,264 & 95,967 & & & & & & \\
\hline 15 & ,337 & 2,106 & 98,073 & & & & & & \\
\hline 16 & ,308 & 1,927 & 100,000 & & & & & & \\
\hline
\end{tabular}

Fonte: Autoria própria (2021). 
Dessa forma, após rodar a AFE, pode-se concluir através da análise da matriz após a rotação dos fatores, descritos como subgrupos, obtém- se que o fator I que representa "A realidade do limite do crescimento" é responsável por 21,525\% da variância explicada (Favero et al., 2009). Esse fator é composto pelos itens 1- Nós estamos chegando ao número de pessoas que a Terra pode suportar; 6- A terra tem riquezas em fontes naturais, nós temos apenas que aprendermos a desenvolvê-las; e, 11- A terra é uma espaçonave com espaço e fontes muito limitados.

O fator II que representa que representa o subgrupo II "anti-antropocentrismo" é responsável por 14,464\% da variância explicada. Esse fator é composto pelos índices 2-Os seres humanos têm o direito de modificar o ambiente natural para atingir suas necessidades. 7-Plantas e animais têm tanto direito de existir quanto os seres humanos. 12- O ser humano foi feito para reinar sobre o resto da natureza.

O subgrupo III, analisado no fator III que representa "a fragilidade do equilíbrio natural" é responsável por 10,496\% da variância explicada. Esse fator é composto pelos itens 3. Quando os seres humanos interferem na natureza, se produz frequentemente consequências desastrosas; 8. O equilíbrio natural é suficientemente estável para absorver os impactos das nações industriais modernas; 13 . O equilíbrio natural é muito delicado e facilmente abalado.

O fator IV que representa o subgrupo IV- "exclusão do ser humano da natureza" é responsável por 8,026\% da variância explicada. Esse fator é composto pelos itens 4. A perspicácia humana irá assegurar que nós NÃO faremos a Terra inabitável; 9. Apesar de nossas habilidades especiais, os seres humanos seguem sujeitos as leis da natureza; 14. Os seres humanos irão aprender o suficiente sobre como a natureza funciona para serem capazes de controlá-la.

O fator V que representa o subgrupo V- "Iminência de crise ecológica" é responsável por 7,599\% da variância explicada. Esse fator é composto pelos itens 5- Os seres humanos estão abusando seriamente do meio ambiente; 10- A chamada "Crise Ecológica" que enfrenta a humanidade tem sido grandemente exagerada; 15- Se as coisas continuarem no curso atual, nós iremos breve experimentar uma catástrofe ecológica maior.

Conforme, a AFE os subgrupos em disposição relacionada a junção dos cinco fatores responde a $62,11 \%$ da questão principal, visto que ao nível de sig. de 5\%, a aceitabilidade é de $\alpha>0,55$, possibilitando aferir do estudo em tela que, as pessoas que consumem produtos second hand possuem um mensuração favorável a questão da consciência ambiental, conforme dados do estudo realizado.

\section{Considerações Finais}

As recentes preocupações com o comportamento do consumidor do fast fashion desperta a reflexão crítica sobre o tema, e vem, também, apresentando outros oportunidades de modelos de negócios para os consumidores de moda consciente e sustentável, como é o caso da moda second hand.

Essa ideia de consumir de forma consciente é estabelecida desde a década de 60, mas somente em pleno século XXI ganhou força com a nova concepção, ou releitura, dos produtos usados, em especial da moda, uma vez que outrora a roupa de segunda mão traduzisse baixo poder aquisitivo e marginalização, atualmente, é sinônimo de comportamento eco socialmente responsável, abarcando cada vez mais um maior número de consumidores.

Daí a importância de acrescer a este cenário mais uma pesquisa que estuda o comportamento do consumidor, que inova na perspectiva, à medida que foca diretamente aqueles que são frequentadores de brechós, quanto a sua potencial consciência ambiental. E, assim, apresenta-se um tema que norteia aspectos do comportamento do consumidor, com foco em um segmento específico que são os consumidores de brechós, ou moda second hand.

A utilização da escala NEP foi essencial à pesquisa, uma vez que possibilitou um retorno dos respondentes de forma bem objetiva, alcançando um número de 103 questionários respondidos, o que possibilitou a aplicação de estatísticas 
exploratória para tratamento dos dados, utilizando uma AFE, cuja resposta ao modelo se deu em torno de $62,11 \%$ e reforçando a validação da pesquisa, conforme disposição na análise de dados.

Conforme dados expostos, pode-se visualizar a existência de uma consciência ambiental por parte dos respondentes, uma vez que, a exemplo do construto formado pelo subgrupo de itens I- A Realidade do Limite do Crescimento, a maioria dos participantes- respondentes optaram por Concordar, ou Concordar Totalmente, com as afirmativas, que explicam em maior grau o construto da consciência ambiental (21,55\%, tab. 06), sobre ações de destruição da terra.

Como os achados direcionam à existência de uma consciência ambiental por parte daqueles respondentes que compuseram a pesquisa, entende-se que há uma consciência ambiental por parte dos consumidores de moda em brechós, e reforçando outras pesquisas mencionadas no texto e nas referências sobre o tema, que seguem na linha de uma abordagem crítica e tratam dos consumidores de second hand realizam consumo sim, por sua consciência ambiental ou crítica.

A pesquisa atingiu seus objetivos e deixa como contribuição um estudo focal no tema sobre a consciência ambiental dos consumidores de produtos second hand. Sugere-se a ampliação deste assunto em estudos futuros, para observação de outros aspectos relacionados ao tema.

\section{Referências}

AKATU - Instituto. (2013). Pesquisa Akatu 2012 - Rumo à sociedade do Bem-Estar: Assimilação e Perspectivas do Consumo Consciente no Brasil Percepção da Responsabilidade Social Empresarial pelo Consumidor Brasileiro.: Instituto Akatu.

Anderson Jr., W. T., \& Cunningham, W. H. (1972). The Socially Conscious Consumer. Journal of Marketing, 36, 23-31.

Antunes, P. de B. (2015). Direito Ambiental: Uma Abordagem Conceitual. 2, Ed. Atlas.

Bianchi, C., \& Birtwistle, G. (2010). Sell. Give Away, or Donate: An Exploratory Study of Fashion Clothing Disposal Behaviour in Two Countries. The International Review of Retail, Distribution and Consumer Research, 20(3), 353-368.

Caldas, D. (2017). Universo da Moda. 2017.

Catton Jr, W. R., \& Dunlap, R. E. (1980). A New Ecological Paradigm For A Post Exuberant Sociology. American Behavioral Scientist. $24,15-47$.

Chiarette, D. (2019). Revista Valor Econômico. Nairóbi, Quênia. https://valor.globo.com/empresas/coluna/industria-da-moda-polui-mais-que-navios-e-avioes1.ghtml

Cortina, J. M. (1993). What Is Coefficient Alpha? An Examination of Theory and Applications. Journal of Applied Psychology. 78, 98-104.

De Toni, D., Larentis, F., \& Mattia, A. (2012). Consumo Consciente, Valor e Lealdade em Produtos Ecologicamente Corretos. Revista de Administração FACES Journal, 11(3), 136-156.

Dunlap, R., \& Van Liere, K. D. (1984). Commitment to The Dominant Social Paradigm and Concern for Environmental Quality. Social Science Quarterly. 65, 1013-1028.

Dunlap, R. E., \& Van Liere, K. D. (1978). The New Environmental Paradigm: A Proposed Measuring Instruments and Preliminary Results. The Journal of Environmental Education. 9, 10-19.

Dunlap, R. E. (1980). Paradigmatic Change in Social Science. From Human Exemptions to an Ecological Paradigm. American Behavioral Scientist. $24,5-14$.

Dunlap, R. E., Van Liere, K. D., Mertig, A. G., \& Jones, R. E. (2000). Measuring Endorsement of The New Ecological Paradigm: A Revised Nep Scale. Journal of Social Issues. 56, 425- 442.

Fávero, L. P., Belfiore, P., Silva, F. L. Da., \& Chan, B. L. (2009). Análise de dados: modelagem multivariada para tomada de decisões. Rio de Janeiro: Elsevier.

Fletcher, K. (2010). Slow Fashion: An Invitation for Systems Change. 2(2). 259-266.

Fletcher, K., \& Grose, L. (2011). Moda \& Sustentabilidade: Design Para Mudança. Ed. SENAC 191.

Gertner, D., \& Diaz, A. N. (1999). Marketing Na Internet E Comportamento Do Consumidor: Investigando A Dicotomia Hedonismo Vs. Utilitarismo Na Www. RAC. 3(30), 131-156.

Guiot, D., \& Roux, D. (2010). A Second-Hand Shoppers' Motivation Scale: Antecedents, Consequences, And Implications For Retailers. Journal of Retailing. $86(4), 383-399$.

Hansen, K. T., \& Zotte, J. L. (2019). Changing Secondhand Economies, Business History. 61(1), 1-16. 10.1080/00076791.2018.1543041 
Research, Society and Development, v. 11, n. 3, e17211326350, 2022

(CC BY 4.0) | ISSN 2525-3409 | DOI: http://dx.doi.org/10.33448/rsd-v11i3.26350

La Trobe, H. L., \& Acott, T. G. (2000). A modified NEP/DSP environmental attitudes scale. The Journal of Environmental Education, 32(1), 12-20.

Kotler, P., \& Keller, K. L. (2006). Administração de Marketing. Pearson Prentice Hall.

Las Casas, A. L. (2012). Administração De Marketing: conceitos, planejamento e aplicações à realidade brasileira. Atlas.

Lipovetsky, G. (2007). A Felicidade Paradoxal: Ensaio Sobre A Sociedade De Hiperconsumo. Cia. das Letras.

Maloney, M. P., Ward, M. P., \& Braucht, G. N. (1975). A revised scale for the measurement of ecological attitudes and knowledge. American Psychologist. 30(7), 787-790.

Mcquillan, H., \& Rissanen, T. (2011). Yield: Making Fashion Without Making Waste. Disponível em: http://yieldexhibition.com/yieldexhibition-catalogue.pdf. Pereira, A. O. K., \& Horn, L. F. D. R. (Org.). (2013). Relações de Consumo: Tecnologia e Meio Ambiente. EDUCS, p. 304

Pereira, S. J. N., \& Ayrosa, E. A. T. (2004). Atitudes Relativas a Marcas e Argumentos Ecológicos: Um Estudo Experimental. Revista Gestão. 2 (2).

Perez, I. U., \& Martins, S. B. (2013). Waste Prevention in The Clothing and Fashion Sector: Innovation in The Design Process. 6(1).

Pirages, D. C. (1977). The Sustainable Society. New York: Praeger.

Roberts, J. A. (1996) Green Consumers in The 1990: Profile and Implications for Advertising. Journal of Business Research, 36, $217-231$.

Roberts, J. A., \& Bacon, D. R. (1997). Exploring The Subtle Relationship Between Environmental Concern and Ecologically Conscious Consumer Behavior. Journal of Business Research, v. 40, 79-89.

Saffi, B. (2015). Brasília Escala Humana: Upcycling com Tecido Descartado para a Marca Pau-Brasília. Universidade de Brasília, Brasília.

Sánchez-Vázquez, P., Gago-Cortés, C., \& Alló-Pazos, M. (2020). Moda Sostenible y Preferencias Del Consumidor. 3c Empres. 9, (3), 39-57.

Schaefer, A., \& Crane, A. (2005). Addressing Sustainability and Consumption. Journal of Macromarketing, 25(1), 76-92.

Sheth, J. N., Mittal, B., \& Newman, B. I. (2001). Comportamento do Cliente: Indo Além do Comportamento do Consumidor. São Paulo: Atlas.

Silva Filho, J. C. et al. (2010). Estudo Sobre O Novo Paradigma Ecológico (Npe) No Brasil: Medindo A Consciência Ambiental Através Da Escala-Nep. XXXIV Encontro ENANPAD.

Solomon, M. R. (2011). O Comportamento do Consumidor: Comprando, Possuindo e Sendo. Bookman.

Williams, C. C. (2003). Explaining Informal and Second-Hand Goods Acquisition. Reader In Economic Geography, 23. University of Leicester, Leicester. 